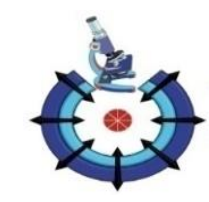

ASRT
Bulletin of Faculty of Science - Zagazig University

https://bfszu.journals.ekb.eg

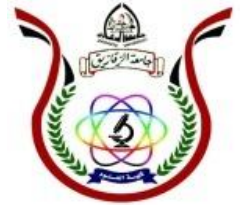

FS-ZU

\title{
Analysis of Total Flavonoids in Herbal Drugs Expressed as Quercetin by Reversed Phase-UHPLC Method
}

\author{
Khaled Elgendy ${ }^{1}$, Mounir Zaky ${ }^{1}$, Akram El-didamony ${ }^{1}$, Badr Abd El-wahaab, Mohamed Aly Amin ${ }^{2}$ \\ ${ }^{1}$ Faculty of Science, Chemistry Department, Zagazig University, Zagazig 44519, Egypt \\ ${ }^{2}$ Technical Manager, Pt CELL for Pharmaceutical Industries $10^{\text {th }}$ of Ramadan city, Egypt
}

\section{ARTICLE HISTORY}

Received: 27 May 2020

Revised: 18 June 2020

Accepted: 18 June2020

\section{KEY WORDS}

UHPLC,

Flavonoids,

Quercetin, Herbal Drugs

\begin{abstract}
A rapid and accurate reversed phase-UHPLC method is developed for determination of gallic acid, quercetin and kaempferol in herbal drugs found in herbal product purchased from local market. A reversed phase chromatographic analysis is carried out under isocratic conditions using column Phenomenex, Prodigy, ODS3, $5.0 \mu \mathrm{m}, 100 \mathrm{~A}, 250$ $\times 4.6 \mathrm{~mm}$ (USA). The mobile phase is methanol and $0.5 \%$ phosphoric acid $(50: 50 \mathrm{v} / \mathrm{v})$. The flow rate is $1.3 \mathrm{~mL} \mathrm{~min}^{-1}$. The injection volume is $20 \mu \mathrm{L}$. The detection wavelength $\left(\lambda_{\max }\right)$ is $370 \mathrm{~nm}$ using a PDA (photodiode array detector). Linearity of the method is established over the concentration ranges of $240-960 \mu \mathrm{g} \mathrm{mL}^{-1}$ for quercetin with a retention time about 7.8 minutes. Correlation coefficient is greater than 0.99 . The recovery level of quercetin is $99.94 \%$. The described method is quite suitable for routine analysis of herbal drugs by reversed phase-UHPLC Method. The proposed method is used for routine analysis to estimate the selected polyphenols under study in its pure form as well as in some herbal drugs forms.
\end{abstract}




\section{INTRODUCTION}

Phenolic compounds are usually known as secondary metabolites which widely distributed in the plant kingdom [1]. They are synthesized partially in plants as a result to physiological and ecological pressures such as insect attack, pathogen, wounding and ultraviolet radiation [2]. They are act as antioxidants due to their abilities to break radical chain reactions, scavenge free radicals, chelate metals, donate hydrogen and quench singlet oxygen in vivo and in vitro [3]. They are bioactive compounds required in preservation of human health from chronic degenerative diseases and generally originated from many sources such as plants, cereals, vegetables, fruits and coffee. Phenolic compounds are classified into many important classes, while the main classes are flavonoids, phenolic acids, phenolic alcohols, lignans and stiblins. Phenolic compounds have two main classes, the first is flavonoids and the other is phenolic acids $[4,5]$.

Flavonoids are a large class of the most common phenolic compounds which widely present in plant tissues and frequently responsible for their purple, blue, red, orange and yellow colors besides the chlorophylls and carotenoids. The flavonoid family is classified into subclasses including flavonols, flavones, iso-flavonols, anthocyanidins, proanthocyanidins, anthocyanins and catechins [6,7]. All flavonoids are consisted of threemembered ringed structures and obtained from tyrosine, phenyalanine and the aromatic amino acids [8]. They are an essential component in a set of medicinal, pharmaceutical, cosmetic and nutraceutical applications. They also have a variety of health promoting effects. This is as a result to their capacity to modify enzyme functions besides their anti-carcinogenic, antimutagenic, anti-inflammatory and anti-oxidative properties [9].

Phenolic acids are one of the other essential classes of phenolic compounds through the plant kingdom which occurred in the form of amides, esters and glycosides, while they are scarcely occurred in free form such as syringic, ferulic, caffeic, gallic, p-coumaric, vanillic, sinapic and protocatechuic acids $[10,2]$.
Gallic acid; or called 3,4,5 trihydroxybenzoic acid $\left[\mathrm{C}_{6} \mathrm{H}_{2}(\mathrm{OH})_{3} \mathrm{CO}_{2} \mathrm{H}\right]$ (Fig. 1a), is a polyphenyl natural product which found in sumac, gallnuts, oak bark, tea leaves and other numerous plants. It is produced from the hydrolysis of tannin with sulphuric acid. It has a great interest due to its pharmacological activity as radical scavenging, anti-fungal, antioxidative, chemo-protective and antiinflammatory activities. It also has potential preventive and therapeutic effects in several diseases including neurodegenerative disorders, cardiovascular diseases, cancer and aging $[11,12]$.

Quercetin, or 3,3',4',5,7-pentahydroxy-2phenylchromen-4-one $\left[\mathrm{C}_{15} \mathrm{H}_{10} \mathrm{O}_{7}\right]$ (Fig. 1b), is a bioflavonoid or flavonoid compound, classified as a flavonol and as water-soluble pigments which cannot be produced by human [13]. Querectin is present in several medicinal plants, vegetables and fruits including apples, cherries, red grapes, onions, kales, broccoli and berries besides tea and red wine; it generally occurred in them not only in its free form but also in the form of glycosides [14,15].

Kaempferol or 3,5,7-trihydroxy-2-(4hydroxyphenyl)-4H-1-benzopyran-4-one [ $\left.\mathrm{C}_{15} \mathrm{H}_{10} \mathrm{O}_{6}\right]$ (Fig. 1c), is a yellow compound act as one of the main encountered aglycone flavonoids in the form of glycoside. It is a tetrahydroxyflavone in which the four hydroxy groups are situated at positions 3, 5, 7, and 4'. Kaempferol is present in several medicinal plant parts and plant derived foods such as seeds, flowers, fruits, leaves and vegetables [16, 17]. Kaempferol innervates the walls of blood vessels and stabilizes the structure of connective tissue. Also, it is displayed antiallergic, antiinflammatory, antifungal and spasmolytic properties [18].

Therefore, the aim of the present study is to determine main flavonoids, gallic acid, quercetin and kaempferol present in herbal drugs by reversed phase UHPLC. 


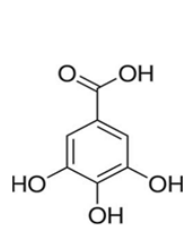

(a)

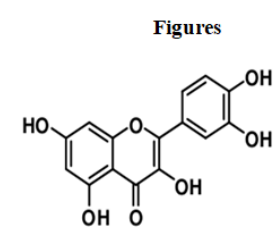

(b)

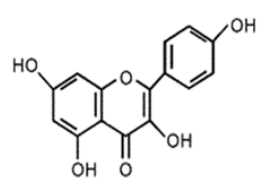

(c)
Fig. (1): Structure of (a) gallic acid, (b) quercetin and (c) Kaempferol

\section{EXPERIMENTAL}

\subsection{Apparatus}

The UHPLC Waters with PDA Detector (Milford, USA) equipped with model Quaternary solvent manager-R pump, PDA detector type HPLC $2998800 \mathrm{~nm}$ is used for the analysis. Peak areas are integrated using a Waters LC solution Empower 3 software (version 1.65.2163) program. A NSXX sonics ultrasonic bath (NS-A-12-7H, Germany) is used for degassing the mobile phase.

\subsection{Chemicals and reagents}

Reference standards of gallic acid, quercetin and kaempferol are obtained from Sigma Aldrich. HPLC grade methanol is obtained from Romil (England). Water for chromatography is purchased from Merck (Germany). Hydrochloric acid $37 \%$ is HPLC grade from Merck (Germany). Ortho-Phosphoric acid $85 \%$ is HPLC grade from Fluka chemicals (Germany).

\subsection{Preparation of standard solution}

A $24 \mathrm{mg}$ of quercetin are dissolved in 20 $\mathrm{mL}$ methanol in $25 \mathrm{~mL}$ volumetric flask, then complete to volume with methanol and sonicate for 10 minutes (standard solution A). Standard solutions are prepared and further diluted with methanol to contain a mixture of quercetin in the linearity range from $240-960 \mu \mathrm{g} \mathrm{mL}^{-1}$. It is filtered by using syringe filter $0.22 \mu$ and discarding the first $5 \mathrm{~mL}$ of the filtrate.

\subsection{Preparation of sample solution}

Accurately $5 \mathrm{~g}$ of each herbal drug (Moderately coarse powder) such as guava, tilia, eucalyptus, cherries, capparis spinosa L, red apple, green tea, onion, grape, tomato and rooibos tea is weighted separately. It is transferred to $50 \mathrm{~mL}$ flat bottom flask, $20 \mathrm{~mL}$ methanol, $10 \mathrm{~mL}$ water, $6 \mathrm{~mL}$ hydrochloric acid $37 \%$ are added and sonicated for 10 minutes then cooled to room temperature and methanol is added to the volume (solution A). Accurately $10 \mathrm{~mL}$ from (solution A) is transferred and boiled on water bath at $90{ }^{0} \mathrm{C}$ for 25 min then covered with aluminium foil. Each herbal drug is filtered by using syringe filter $0.22 \mu$ and discarding the first $5 \mathrm{~mL}$ of the filtrate.

\subsection{Analytical procedures}

\subsubsection{Chromatographic conditions}

The separation is performed by UHPLC Waters with PDA Detector (Milford, USA) equipped with model Quaternary solvent manager-R pump, PDA detector type HPLC $2998800 \mathrm{~nm}$. Peak areas are integrated using a Waters LC solution Empower 3 software (version 1.65.2163) program. Experimental conditions are optimized on Phenomenex, Prodigy, ODS3, $5.0 \mu \mathrm{m}, 100$ A, $250 \times 4.6 \mathrm{~mm}$ (USA) and the flow rate of the mobile phase is $1.3 \mathrm{~mL} \mathrm{~min}{ }^{-1}$. The mobile phase is consisting methanol and 0.5\% phosphoric acid (50:50 $\mathrm{v} / \mathrm{v})$. Analysis is performed with injection volume of $20 \mu \mathrm{L}$ using PDA detection at 370 $\mathrm{nm}$. Mobile phase is filtered using $0.22 \mu \mathrm{m}$ nylon membrane filter (UK). The optimized chromatographic condition is showed in Table (1).

Table (1): Optimized chromatographic conditions

\begin{tabular}{ll}
\hline Parameters & Conditions \\
\hline Stationary phase & $\begin{array}{l}\text { Prodigy, ODS3, } 5 \mu \mathrm{m}, 100 \mathrm{~A}, 250 \times 4.6 \mathrm{~mm} \\
\text { Methanol and } 0.5 \% \text { phosphoric acid }(50: 50 \mathrm{v} / \mathrm{v})\end{array}$ \\
$\begin{array}{l}\text { Mobile phase } \\
\text { Flow rate }\left(\mathrm{mL} \mathrm{min}^{-1}\right)\end{array}$ & 1.3
\end{tabular}




\subsubsection{Linearity}

Linear calibration plots of the approach method are obtained through concentration with ranges of $240-960 \mu \mathrm{g} \mathrm{mL}^{-1}(240,384,480$, 768 and $960 \mu \mathrm{g} \mathrm{mL}^{-1}$ ) for quercetin. Triplicate injections are used to each standard solution.

\subsubsection{Accuracy}

Accuracy is estimated by the standard addition method of quercetin, gallic acid and kaempferol. In this method, a known quantity of quercetin, gallic acid and kaempferol are added to the formerly analyzed sample solution and there after experimental and true values are compared. Three levels are made corresponding to $80 \%, 100 \%$ and $160 \%$ of the nominal analytical concentration.

\subsubsection{Precision}

Repeatability is investigated using intra-day and inter-day precision. Intra-day precision is counted by injecting 5 replicates of 3 diverse concentrations on the same day. Interday precision is determined by injecting the same solutions for 3 sequential days. Relative standard deviation (RSD \%) of the peak area is determined to appear precision.

\subsubsection{Robustness}

The method robustness is investigated by studying the premeditate variations in the experimental conditions of the proposed method. For this goal, minor changes have occurred in the mobile phase composition, flow rate and $\mathrm{pH}$ of buffer solution. The effect of these changes on chromatographic parameters which include tailing factor, retention time and number of theoretical plates is measured.

\subsubsection{Limit of detection (LOD) and limit of quantitation (LOQ)}

LOD is counted agreeing to the expression $3.3 \sigma / \mathrm{S}$, where $\sigma$ is the standard deviation of the response and $S$ is the slope of the calibration curve. LOQ is determined by using the expression $10 \sigma / \mathrm{S}$. LOD and LOQ are experimentally verified by injections of the pure standard at the LOD and LOQ concentrations.

\section{RESULTS AND DISCUSSION}

The variations in the mobile phase composition and different stationary phases have essential influences on peak shape, retention factor, tailing factor, resolution and theoretical plates. The goal of this work is to improve a method that can be used successfully for determination and separation of the studied herbal drugs. This method is a simple, selective, sensitive and accurate of UHPLC method. Simultaneous determination of gallic acid, quercetin and kaempferol, either separate or in herbal drugs in this method is adopted. The comparison between the amounts of different flavonoids in different herbal drugs is established as showed in Table (2). There is a clear resolution between gallic acid, quercetin and kaempferol with the retention time of 4.3, 7.9 and 14.9 min., respectively. Method validation is uttered according to ICH guidelines [19].

Table (2): comparison between the amounts of flavonoids in different herbal drugs

\begin{tabular}{lccc}
\hline Herbal drug & Quercetin $(\mathrm{mg})$ & Gallic acid $(\mathrm{mg})$ & Kaempferol $(\mathrm{mg})$ \\
Tilia & 750 & 620 & 600 \\
Eucalyptus & 714 & 590 & 627 \\
Capparis spinosa L & 674 & 520 & 496 \\
Guava & 717 & 640 & 603 \\
\hline
\end{tabular}




\begin{tabular}{llll}
\hline Cherries & 500 & 499 & 436 \\
Red apple & 400 & 400 & 410 \\
Grape & 500 & 580 & 570 \\
Tomato & 300 & 318 & 400 \\
Onion & 520 & 589 & 610 \\
Rooibos tea & 583 & 600 & 613 \\
Green tea & 742 & 620 & 640 \\
\hline
\end{tabular}

\subsection{Method validation}

Method validation is established that the method performance characteristics are suitable for the intended use. Validation is entailed an evaluation of various parameters of the method such as linearity, accuracy, precision, robustness, detection and quantification limits.

\subsubsection{Linearity}

The linearity of the method is estimated and it is clear within the concentration range of 240 obvious by the high value of the correlation coefficient as showed in (Figs. 2, 3). Linear regression equation is described by the correlation between the analyte concentration and peak area with high value of correlation coefficient $\left(\mathrm{R}^{2}\right)$, Table (3). The regression equation is calculated and found to be:

$\mathrm{Y}_{1}=23405.78145, \mathrm{C}_{1}=36159.88647, \mathrm{R}^{2}=$ 0.99988

Where $\mathrm{Y}_{1}$ is the peak area/ $10^{3}, \mathrm{C}_{1}$, is concentrations of quercetin in $\mu \mathrm{g} \mathrm{mL}^{-1}$ and $\mathrm{R}^{2}$ is the correlation coefficient.

$-960 \mu \mathrm{g} \mathrm{mL} \mathrm{m}^{-1}$ for quercetin. Good linearity is

Table (3): Characteristics of the proposed methods used in assay of quercetin

\begin{tabular}{ll}
\hline Parameters & Quercetin \\
\hline Linearity range $\left(\mu \mathrm{g} \mathrm{mL}^{-1}\right)$ & $240.0-960.0$ \\
Slope & 23405.78145 \\
Intercept (a) & -36159.88647 \\
Correlation coefficient & 0.99988 \\
Detection limit $\left(\mu \mathrm{g} \mathrm{mL}^{-1}\right)$ & 33.34 \\
Quantification limit $\left(\mu \mathrm{g} \mathrm{mL}^{-1}\right)$ & 100.0 \\
Capacity factor & 0.00 \\
Tailing factor & 1.13 \\
Theoretical plate no. & 4011 \\
\hline
\end{tabular}

Regression equation: $\mathrm{Y}=\mathrm{a}+\mathrm{bC}$, where $\mathrm{Y}$ was the area under peak, $\mathrm{a}$ : was the intercept, $\mathrm{b}$ : was the slope and $\mathrm{C}$ : was the concentration.

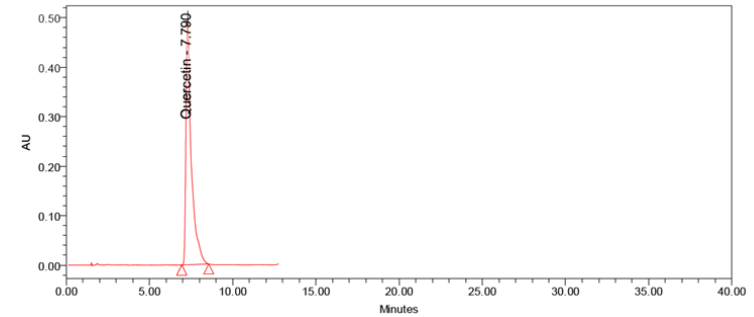

Fig. (2): A typical chromatogram of quercetin standard drug.

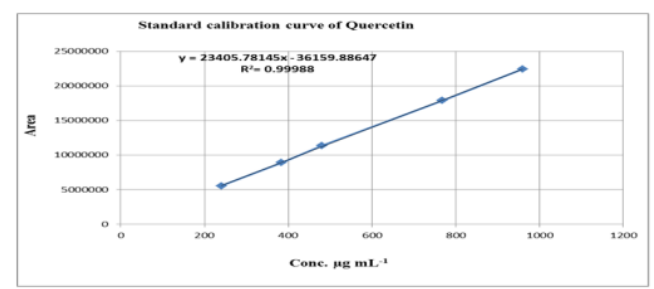

Fig. (3): Calibration curve of quercetin.

\subsubsection{Accuracy}

Accuracy and recovery of the method are conformed by using the standard addition technique on different pharmaceutical forms, Table (4) and Figures (4-14) are showed no interference from excipients and good accuracy of the method. Three levels of solutions of the nominal analytical concentrations (80, 100 and $160 \%)$ are prepared then analyzed by the developed method. The average percentage recovery of the three polyphenols was $99.94 \%$, $99.99 \%$ and $100.04 \%$ for quercetin, gallic acid and kaempferol, respectively. The relative standard deviation (RSD \%) was found to be $0.06,0.10$ and 0.13 for quercetin, gallic acid and kaempferol, respectively. 
Table (4): Accuracy of the proposed UHPLC method

\begin{tabular}{|c|c|c|c|c|c|c|c|c|c|}
\hline \multirow[b]{2}{*}{$\begin{array}{l}\text { Level } \\
(\%)\end{array}$} & \multicolumn{3}{|c|}{ Gallic acid } & \multicolumn{3}{|c|}{ Quercetin } & \multicolumn{3}{|c|}{ Kaempferol } \\
\hline & $\begin{array}{l}\text { Amount } \\
\text { of drug } \\
\text { spiked } \\
(\mathrm{mg})\end{array}$ & $\begin{array}{c}\text { Found } \\
(\mathrm{mg})\end{array}$ & $\begin{array}{c}\text { Recover } \\
(\%) y \\
(n=3)\end{array}$ & $\begin{array}{l}\text { Amount } \\
\text { of drug } \\
\text { spiked } \\
(\mathrm{mg})\end{array}$ & $\begin{array}{c}\text { Found } \\
(\mathrm{mg})\end{array}$ & $\begin{array}{c}\text { Recovery } \\
(\%) \\
(n=3)\end{array}$ & $\begin{array}{l}\text { Amount } \\
\text { of drug } \\
\text { spiked } \\
(\mathrm{mg})\end{array}$ & $\begin{array}{l}\text { Found } \\
\text { (mg) }\end{array}$ & $\begin{array}{c}\text { Recover } \\
(\%) y \\
(n=3)\end{array}$ \\
\hline 80 & 320.22 & 319.84 & 99.88 & 384.12 & $\begin{array}{c}383.9 \\
4\end{array}$ & 99.95 & 320.24 & 320.11 & 99.96 \\
\hline 100 & 400.74 & 400.80 & 100.01 & 480.81 & $\begin{array}{c}480.1 \\
7\end{array}$ & 99.87 & 400.17 & 400.01 & 99.96 \\
\hline \multirow[t]{4}{*}{160} & 639.54 & 640.01 & 100.07 & 768.74 & $\begin{array}{c}768.6 \\
6\end{array}$ & 99.99 & 639.01 & 640.24 & 100.19 \\
\hline & \multicolumn{2}{|c|}{ Average Recovery } & 99.99 & \multicolumn{2}{|c|}{$\begin{array}{l}\text { Average } \\
\text { Recovery }\end{array}$} & 99.94 & \multicolumn{2}{|c|}{ Average Recovery } & 100.04 \\
\hline & \multicolumn{2}{|c|}{ SD } & 0.10 & \multicolumn{2}{|c|}{ SD } & 0.06 & \multicolumn{2}{|c|}{ SD } & 0.13 \\
\hline & \multicolumn{2}{|c|}{$\% \mathrm{RSD}$} & 0.10 & \multicolumn{2}{|c|}{$\%$ RSD } & 0.06 & \multicolumn{2}{|c|}{$\%$ RSD } & 0.13 \\
\hline
\end{tabular}

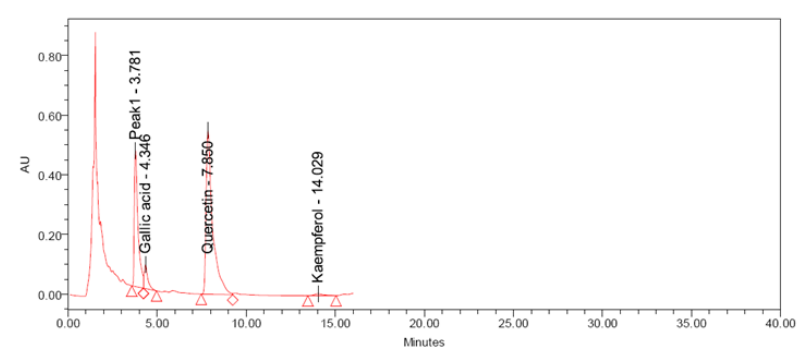

Fig. (4): UHPLC chromatogram of guava sample drug

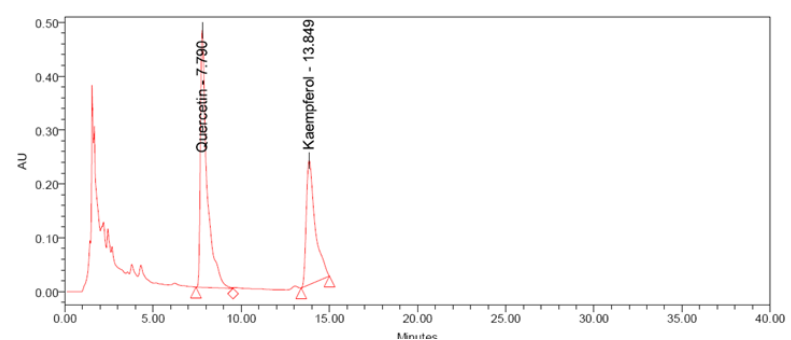

Fig. (5): UHPLC chromatogram of tilia sample drug

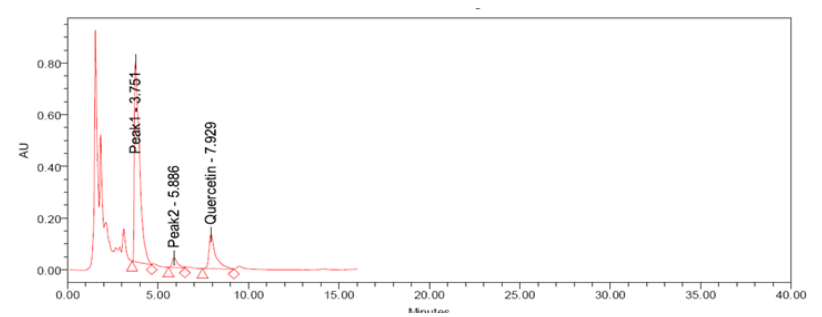

Fig. (6): UHPLC chromatogram of eucalyptus sample drug

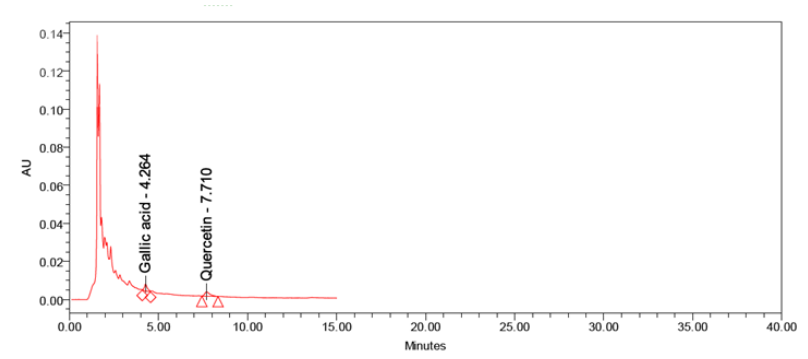

Fig. (7): UHPLC chromatogram of cherries sample drug

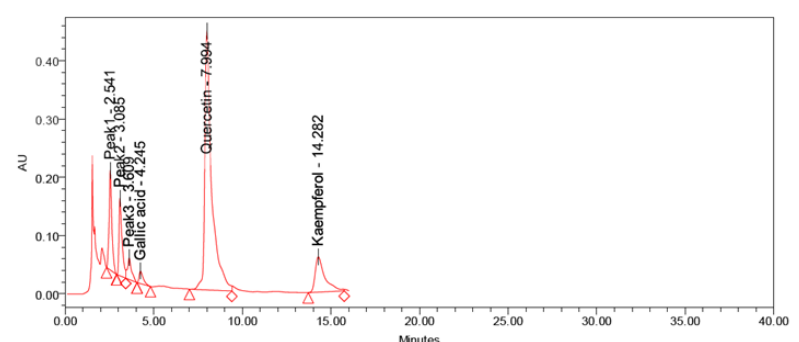

Fig. (8): UHPLC chromatogram of capparis spinosa L. sample drug

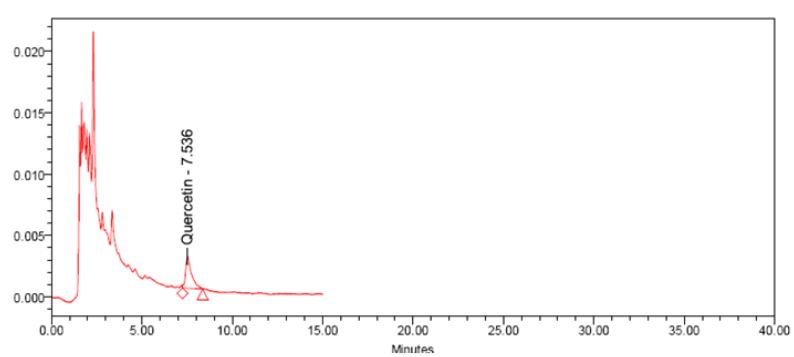

Fig. (9): UHPLC chromatogram of red apple sample drug 


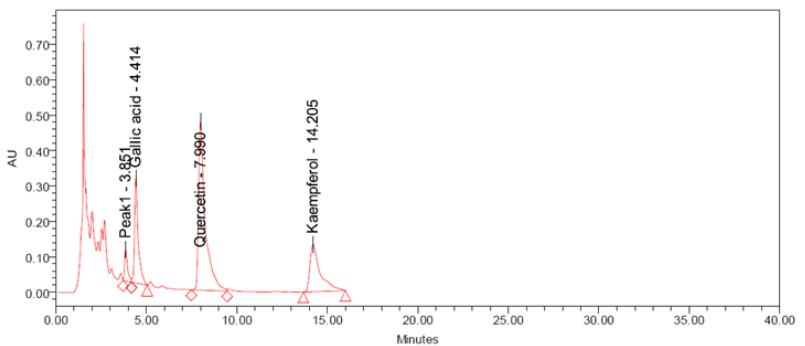

Fig. (10): UHPLC chromatogram of green tea sample drug

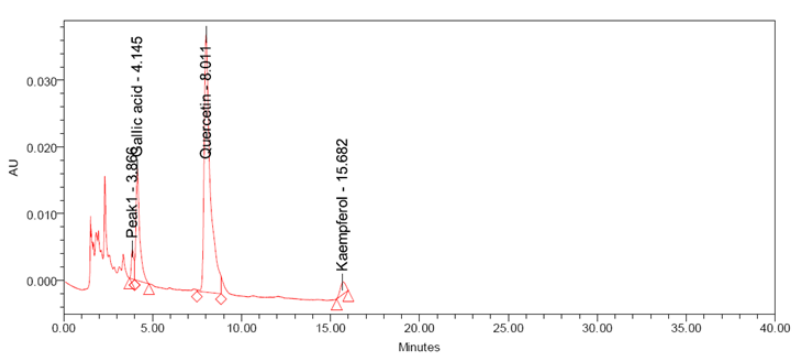

Fig. (11): UHPLC chromatogram of onion sample drug

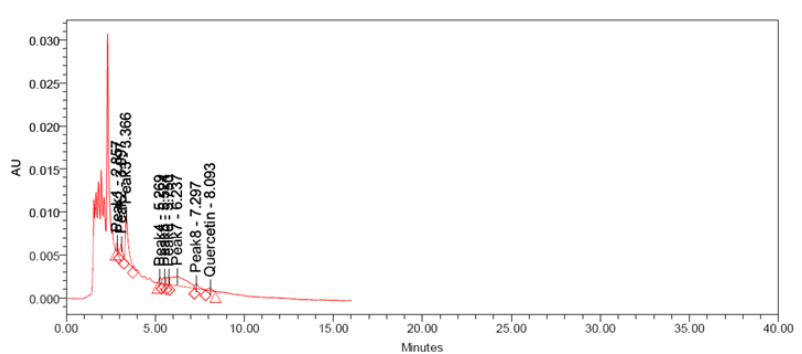

Fig. (12): UHPLC chromatogram of grape sample drug

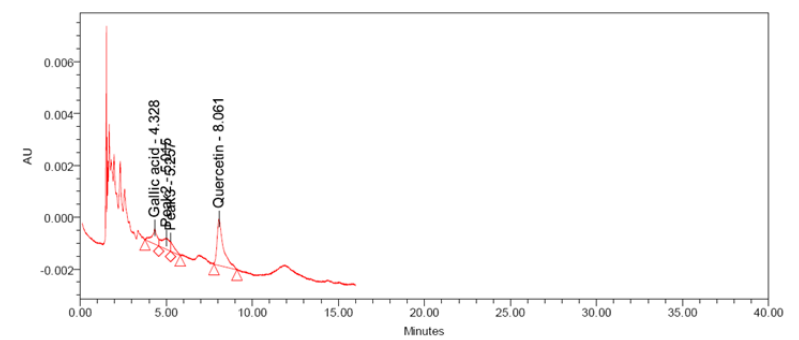

Fig. (13): UHPLC chromatogram of tomato sample drug

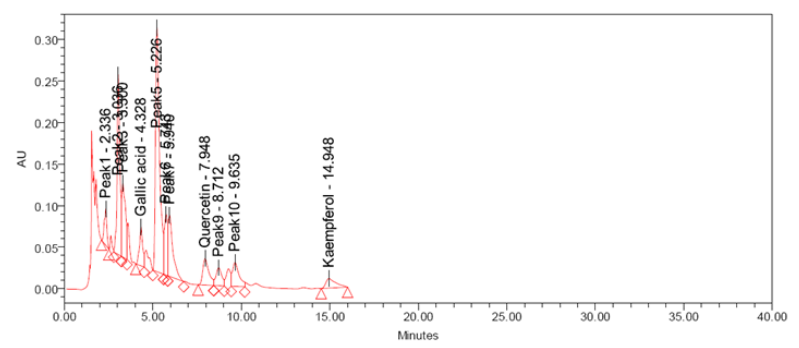

Fig. (14): UHPLC chromatogram of rooibos tea sample drug

\subsubsection{Precision}

Intra-day precision is estimated by injecting 5 standard solutions of 3 different concentrations on the same day and inter-day precision is established by injecting the same solutions for three sequential days. RSD \% of the peak area is counted to represent precision. Results of intra-day and inter-day precision are showed in Table (5).

Table (5): Intra-day and inter-day precision of the proposed UHPLC method.

\begin{tabular}{|c|c|c|c|}
\hline Drugs & $\begin{array}{l}\text { Actual } \\
\text { concentration } \\
\left(\mu \mathrm{g} \mathrm{mL}^{-1}\right)\end{array}$ & $\begin{array}{l}\text { Intra-day precision } \\
\text { measured concentrations } \\
\left(\mu \mathrm{g} \mathrm{mL} \mathrm{L}^{-1}\right) ; \mathrm{RSD}(\%)\end{array}$ & $\begin{array}{l}\text { Inter-day precision } \\
\text { measured } \\
\text { concentrations } \\
\left(\mu \mathrm{g} \mathrm{mL}^{-1}\right) ; \mathrm{RSD}(\%)\end{array}$ \\
\hline Quercetin & $\begin{array}{l}80 \\
100 \\
160 \\
\end{array}$ & $\begin{array}{l}79.82 ; 1.05 \\
100.04 ; 0.10 \\
160.12 ; 0.42 \\
\end{array}$ & $\begin{array}{l}80.11 ; 0.46 \\
100.24 ; 0.34 \\
159.81 ; 0.21\end{array}$ \\
\hline
\end{tabular}

Table (6): Robustness study of quercetin.

\begin{tabular}{lllll}
\hline $\begin{array}{l}\text { Chromatographic } \\
\text { conditions }\end{array}$ & $\begin{array}{l}\text { Assay } \\
(\%)\end{array}$ & $\begin{array}{l}\mathrm{t}_{\mathrm{R}} \\
(\mathrm{min})\end{array}$ & $\begin{array}{l}\text { Theoretical } \\
\text { plates }\end{array}$ & Tailing \\
\hline $\begin{array}{l}\text { Column temperature } \\
\left(20^{\circ} \mathrm{C}\right)\end{array}$ & 100.11 & 7.81 & 4012 & 1.13
\end{tabular}




\begin{tabular}{|c|c|c|c|c|}
\hline $\begin{array}{l}\text { Column temperature } \\
\left(25^{0} \mathrm{C}\right)\end{array}$ & 100.14 & 7.80 & 4014 & 1.12 \\
\hline $\begin{array}{l}\text { Column temperature } \\
\left(30{ }^{0} \mathrm{C}\right)\end{array}$ & 99.97 & 7.79 & 4021 & 1.13 \\
\hline $\begin{array}{l}\text { Flow rate }\left(1.4 \mathrm{~mL} \mathrm{~min}^{-}\right. \\
\left.{ }^{1}\right)\end{array}$ & 99.19 & 7.78 & 4017 & 1.15 \\
\hline $\begin{array}{l}\text { Flow rate }\left(1.3 \mathrm{~mL} \mathrm{~min}^{-}\right. \\
\left.{ }_{1}\right)\end{array}$ & 99.84 & 7.79 & 4024 & 1.15 \\
\hline $\begin{array}{l}\text { Flow rate }\left(1.2 \mathrm{~mL} \mathrm{~min}^{-}\right. \\
\left.{ }_{1}\right)\end{array}$ & 100.01 & 7.81 & 4022 & 1.14 \\
\hline Buffer (pH 2.2) & 99.88 & 7.81 & 4012 & 1.13 \\
\hline Buffer (pH 2.1) & 99.15 & 7.78 & 4011 & 1.16 \\
\hline Buffer (pH 2.0) & 99.84 & 7.78 & 4013 & 1.10 \\
\hline
\end{tabular}

\subsubsection{Limit of detection (LOD) and limit of quantitation (LOQ)}

LOD and LOQ are determined by preparing of serial dilutions. LOD is found to be $33.34 \mu \mathrm{g}$ $\mathrm{mL}^{-1}$ for quercetin (signal to noise ratio of 3:1). LOQ is found to be $100.0 \mu \mathrm{g} \mathrm{mL}^{-1}$ for quercetin (signal to noise ratio of 10:1).

\subsection{Suitability of the chromatographic system}

System suitability tests are depended on the concept that the analytical operations, equipment, electronics, and samples constitute an integral system that can be estimated as a total. System suitability is used to confirm system performance before or during the analysis of the drugs. System suitability is checked by calculating the asymmetry factor, theoretical plates, tailing factor and resolution where the system is found to be suitable as showed in Table (7).

Table (7): Summary of system suitability tests

\begin{tabular}{ll}
\hline Parameters & Quercetin \\
\hline $\mathrm{T}$ & 1.13 \\
$\mathrm{R}^{\mathrm{b}}$ & - \\
$\mathrm{N}$ & 4011 \\
$\mathrm{AS}$ & 1.11 \\
$\mathrm{RSD}^{\mathrm{a}}$ (peak areas) & 0.92 \\
$\mathrm{RSD}^{\mathrm{a}}$ (retention time) & 0.35 \\
\hline $\mathrm{T}$, Tailing factor; N, no. of theoretical plates; R, \\
resolution factor; As, asymmetry factor. \\
a RSD for five determinations. \\
b The resolution factor (R) calculated to the nearest peak \\
in order.
\end{tabular}

\section{CONCLUSIONS}

The validated reversed phase-UHPLC method is developed for the determination of total flavonoids as gallic acid, quercetin and kaempferol expressed as quercetin in herbal drugs. The developed method is validated by testing its linearity, accuracy, precision, specificity, limits of detection and quantitation. This method enables determination of total flavonoids because of good separation and resolution of the chromatographic peaks. As a result, the proposed UHPLC method can be adopted for quantitative routine analysis.

\section{REFERENCES}

1. Lattanzio V., (2013). Natural products, Chapter: 50. Phenolic Compounds: Introduction. Springer-Verlag Berlin Heidelberg, pp.1543-1580.

2. Khoddami A., Wilkes M.A., Roberts, T.H., (2013). Techniques for analysis of plant phenolic compounds. Molecules, 18: 2328-2375.

3. Zhang A., Wan L., Wu C., Fang Y., Han G., Li H., Zhang Z., Wang H., (2013). Simultaneous determination of 14 phenolic compounds in grape canes by HPLC-DADUV using wavelength switching detection. Molecules, 18: 14241-14257.

4. Abbas M., Saeed F., Anjum F.M., Afzaal M., Tufail T., Bashir M.S., Ishtiaq A., Hussain S., Suleria, H.A.R., (2017). 
Natural polyphenols: An overview. Int. J. Food Prop., 20: 1689-1699.

5. Dragovicuzelac V., Levaj B., Mrkic V., Bursac D., Boras M., (2007). The content of polyphenols and carotenoids in three apricot cultivars depending on stage of maturity and geographical region. Food Chem., 102: 966-975.

6. Ferreira O., Pinho S.P., (2012). Solubility of flavonoids in pure solvents. Ind. Eng. Chem. Res., 51: 6586-6590.

7. Rong T., (2010). Chemistry and biochemistry of dietary polyphenols, Review. Nutrients, 2: 1231-1246.

8. Routray W., Orsat V., (2012). Review: Microwave-assisted extraction of flavonoids. Food Bioprocess. Technol., 5: 409-424.

9. Panche A.N., Diwan A.D., Chandra S.R., (2016). Flavonoids: An overview. J. Nutr. Sci., 5: 1-15.

10. Pereira D.M., Valentao P., Pereira J.A., Andrade P.B., (2009). Phenolics: From chemistry to biology. Molecules, 14: 22022211.

11. Phansawan B., Pongsabangpho S., (2014). Determination of gallic acid and rutin in extracts Cassia alata and Andrographis paniculata. Science Asia, 40: 414-419.

12. Pal S.M., Avneet G., Siddhraj S.S., (2018). Gallic acid: Pharmacogical promising lead molecule: A review. Int. J. Pharmacogn. Phytochem. Res., 10: 132138.

13. Kumar R., Vijayalakshmi S., Nadanasabapathi S., (2017). Health benefits of quercetin. Def. Life Sci. J., 2: 142-151.

14. Dmitrienko S.G., Kudrinskaya V.A., Apyari V.V., (2012). Methods of extraction, preconcentration, and determination of quercetin. J. Anal. Chem., 67: 299-311.

15. Xu D., Hu M.J., Wang Y.Q., Cui Y.L., (2019). Antioxidant activities of quercetin and its complexes for medicinal application. Molecules, 24: 1123-1138.

16. Imran M., Salehi B., Sharifi-Rad J., Gondal T.A., Saeed F., Imran A.,
Shahbaz M., Fokou P.V.T., Arshad M.U., Khan H., Guerreiro S.G., Martins N., Estevinho L.M., (2019). Kaempferol: A key emphasis to its anticancer potential. Molecules, 24: 2277-2292.

17. Calderon-Montano J.M., Burgos-Moron E., Perez-Guerrero C., Lopez-Lazaro M., (2011). A review on the dietary flavonoid kaempferol. Mini-Rev. Med. Chem., 11: 298-344.

18. Palacz-Wrobel M., (2018). HealthPromoting Properties of Apigenin and Kaempferol. Annals Pharmacol. Pharm., 3: 1145-1149.

19. International Committee of Harmonization I.C.H., (2005). Q2(R1) Validation of Analytical Procedures: Methodology. 